\title{
인공증우(설) 항공실험 분석: 2019년 국제공동연구를 대상으로 Analysis of Cloud Seeding Experiment by Aircraft: A Case Study of an International Joint Experiment in 2019
}

\author{
구정모* · 고아름** . 채상희*** · 황현준 $* * * *$. 노용훈 $* * * * *$. 정운선 $* * * * * *$ \\ Ku, Jung Mo*, Ko, A-Reum**, Chae, Sanghee ${ }^{* * *}$, Hwang, Hyun Jun***, Ro, Yonghun****, \\ and Jung, Woonseon ${ }^{* * * * * *}$
}

\begin{abstract}
In this study, an international joint cloud seeding experiment (International Joint Cloud Observation and Weather Control Experiment 2019, IJCO-WCE 2019) by aircraft was analyzed using numerical simulations, ground observation data, and aircraft observation data. As a result of numerical simulations, it was found that the seeding material was diffused in a direction consistent with the wind direction observed by the aircraft. Further, aircraft observation data showed an increase in average water concentration of clouds and precipitation particles after seeding rather than during seeding. The average water concentration of clouds observed by the Cloud Droplet Probe (CDP) increased by about 59\% after seeding than during seeding, and that observed by the Cloud Imaging Probe (CIP) increased by about $82 \%$. In addition, precipitation particles observed by the Precipitation Imaging Probe (PIP) were hardly noticed during seeding, but appeared after seeding.
\end{abstract}

Key words : Cloud Seeding Experiments, IJCO-WCE 2019, Cloud Particles, Precipitation Particles

\section{요 지}

본 연구에서는 항공기를 이용하여 수행된 인공증우(설) 국제공동연구(International Joint Cloud Observation and Weather Control Experiment 2019, IJCO-WCE 2019) 사례를 레이더 자료, 지상관측소 자료, 수치 모의 자료, 항공 관측 자료를 이용하여 인공증우(설) 효과를 분석하였다. 시딩 물질의 확산을 수치 모의한 결과, 시딩 물질은 항공기로 관측된 풍향과 일치한 방향으로 확산한 것으로 나타났다. 항공기 관측자료를 분석한 결과에서는 구름 입자의 평균수농도와 강수 입자가 시딩 중보다 시딩 후에 증가한 것을 확인할 수 있었다. 구름 입자 측정기(Cloud Droplet Probe, CDP)로 관측된 구름의 평균수농도는 시딩 중보다 시딩 후에 약 $59 \%$ 증가하였고, 구름 영상 측정기(Cloud Imaging Probe, CIP)로 관측된 구름의 평균수농도는 약 $82 \%$ 증가하였다. 아울러 강수 입자 측정기(Precipitation Imaging Probe, PIP)로 관측된 강수 입자는 시딩 중에는 거의 관측되지 않았지만 시딩 후에 관측됐다.

핵심용어 : 인공증우(설), 국제공동연구(IJCO-WCE 2019), 구름 입자, 강수 입자

*교신저자, 정회원, 국립기상과학원 융합기술연구부 연구원(Tel: +82-64-780-6694, Fax: +82-64-780-6315, E-mail: kjm1868@korea.kr) Corresponding Author, Member, Researcher, Convergence Meteorological Research Department, National Institute of Meteorological Science

**국립기상과학원 융합기술연구부 연구원

Researcher, Convergence Meteorological Research Department, National Institute of Meteorological Science

****국립기상과학원 융합기술연구부 연구원

Researcher, Convergence Meteorological Research Department, National Institute of Meteorological Science

*****국립기상과학원 융합기술연구부 연구원

Researcher, Convergence Meteorological Research Department, National Institute of Meteorological Science

*****정회원, 국립기상과학원 융합기술연구부 연구원

Member, Researcher, Convergence Meteorological Research Department, National Institute of Meteorological Science

******국립기상과학원 융합기술연구부 기상연구사

Research Scientist, Convergence Meteorological Research Department, National Institute of Meteorological Science 


\section{1. 서 론}

최근 기후변화에 의한 기온과 강수의 변동성이 커지면서, 홍수, 가뭄 등 자연재해가 빈번하게 발생하고 있다(WMO, 2009; Kwon et al., 2018; Kim et al., 2019). 특히, 가뭄은 다른 자연재해에 비해 장기간에 걸쳐 넓은 지역에 심각한 피해를 발생시키므로 이에 대한 대비가 중요하다(Sohn et al., 2015; Baek et al., 2016; Lee and Son, 2016; Yoo et al., 2016; Kim et al., 2019). 일반적으로 수자원을 확보하는 대책으로는 댐 건설, 지하수 개발 등 여러 방법이 있지만 큰 비용과 이에 따른 환경문제도 가지고 있다(NIMR, 2009). 이러한 문제들을 최소화하고 수자원을 확보하는 방안으로 인공증우(설) 기술이 있다.

인공증우(설)는 기상조절(Cloud seeding)에 속하는 기술 로 강수 가능성이 있는 구름층에 인위적으로 구름씨 역할을 하는 시딩 물질(Seeding material)을 뿌려 구름의 발달과 강수 응결을 활성화해 더 많은 강수를 내리게 하거나 다른 지역에 강수를 내리게 하는 기술이다(NIMS, 2018). 즉, 인공 증우는 여름철 강우의 양을 증가시키는 기술이고, 인공증설 은 겨울철 강설의 양을 증가시키는 기술이다. 인공증우(설) 실험은 지상실험과 항공실험으로 구분되며, 지상실험은 지 상에 설치된 지상연소기나 로켓, 드론 등을 이용하여 운저 (Cloud base)를 대상으로 시딩 물질을 연소시키고, 항공실험 은 비행기에 시딩 물질 살포 장치를 탑재하고 운정(Cloud top)에서 시딩 물질을 연소시킨다.

인공증우(설) 실험은 드라이아이스를 가지고 과냉각 물방울 을 얼음 결정으로 성장시키는 연구로부터 시작되었다(Schaefer, 1946; Vonnegut, 1947). 이러한 발견을 시작으로 현재 미국, 일본, 중국, 태국 등 많은 국가에서 다양한 연구 프로젝트로 진행되고 있다(NIMS, 2018). 미국의 와이오밍 주립대학에서는 와이오밍의 3개 산악 지역(Wind River, Sierra Madre, Medicine Bow)을 대상으로 기상조절 실험(Wyoming Weather Modification Pilot Project, WWMPP)을 9년(2006 2014) 동안 수행한 바 있고(Geerts et al., 2010; Geerts et al., 2013; Pokharel and Geerts, 2014), 일본에서는 2006년에 수자원 관리와 가뭄 저감 에 대한 인공증우(설) 실험 효과를 평가하기 위해 JCSEPA 프로젝트(Japanese Cloud Seeding Experiments for Precipitation Augmentation)를 수행하였다(Hashimoto et al., 2008; Ohtake et al., 2014; NIMS, 2016). 중국은 2008년 베이징 올림픽의 성공적인 개막식과 폐막식을 위해 인공증위(설) 실험을 수행 하였고, 최근에는 수자원 확보를 목적으로 항공기, 지상연소 기, 대공포, 로켓 등을 이용하여 인공증위(설) 실험을 진행하 고 있다(Li et al., 2017). 또한, 태국에서는 건기에 가뭄으로 인한 물 부족이 자주 발생하는 문제를 해결하기 위해 농업지원 을 목적으로 인공증우(설) 실험을 수행하고 있다(Silverman and Sukarnjanaset, 2000; Flossmann et al., 2018).

우리나라는 1963 년 양인기 박사에 의해 인공증우(설) 실험
이 시작되었다(NIMS, 2018). 현재는 국립기상과학원에서 수자원 확보, 미세먼지 저감, 산불 예방 등을 목적으로 인공증 우(설) 실험을 수행하고 있다. 국립기상과학원은 2008부터 2017년까지 공군 또는 민간 항공기를 임대하여 인공증우(설) 항공실험을 수행하였다. 그러나 기상 관측장비 탑재와 실험 횟수 등 항공실험을 수행하는 데 있어 제한이 많았고, 이에 국가적 기상관측 기술력 확보를 위한 목적으로 2017년 11월 기상 관측장비들을 탑재한 기상 항공기를 도입하였다. 기상 항공기가 도입되어 이전보다 다양한 목적과 기상조건에 대한 인공증우(설) 항공실험을 수행하고 있지만, 기상 항공기를 이용한 실험설계 및 검증 방법 등은 인공증위(설) 선진기술을 확보한 미국, 일본, 중국 등에 비해 연구가 부족한 상황이다.

국립기상과학원은 선진 인공증우(설) 기술 습득 및 국내 최적화된 인공증우(설) 기술개발을 목적으로 2019년 11월 18 일부터 12 월 20 일까지 미국과 인공증우(설) 국제공동연구 프로젝트(International Joint Cloud Observation and Weather Control Experiment 2019, IJCO-WCE 2019)를 수행하였다. 본 연구에서는 대관령을 대상으로 수행된 국제공동연구에 대한 인공증우(설) 효과를 분석하였다. 2장에서는 기상 항공기 의 특성과 인공증우(설) 항공실험 결정 방법 및 항공실험 설계 방법을 정리하였다. 3 장에서는 항공실험 후 수치 모의 자료와 항공 및 지상 관측 자료를 이용하여 인공증우(설) 효과를 분석 하였다. 아울러 4장에서는 결과를 요약하고, 향후 필요한 인공 증우(설) 효과 분석의 연구 방향을 제시하고자 한다.

\section{2. 인공증우(설) 항공실험}

\section{1 항공실험 개요}

국립기상과학원에서는 정기적인 기상관측 및 기후 변화 대응과 수자원 확보를 위한 기상조절 기술 필요성에 따라 2018년도에 미국 Beechcraft의 King Air 350HW를 기상 항공 기(KMA/NIMS Atmospheric Research Aircraft, NARA)로 도입하였다. 이 항공기는 기상관측 용도에 맞게 개조되었으 며, 총 25 개의 기상 관측장비들이 탑재되어 있다(Fig. 1). 또한, 조종사 2 명과 장비운영자 2 명 및 연구자 1 명으로 총 5 명이 탑승 가능하며, 최대 비행시간은 330 분이다. 기상 항공기에 대한 기본 제원은 Table 1 과 같다.

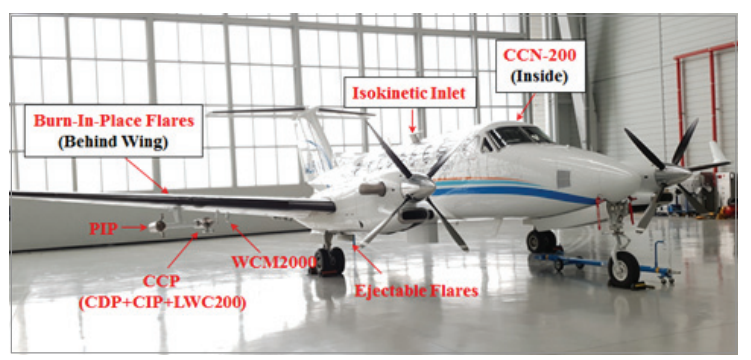

Fig. 1. KMA/NIMS Atmospheric Research Aircraft (NARA, King Air 350HW) 
Table 1. Specifications and Performance of King Air 350HW

\begin{tabular}{c|c}
\hline Specifics & Atmospheric Research Aircraft \\
\hline Type & Beecheraft King Air 350HW \\
\hline Passengers & 5 persons \\
\hline Height/Length/Wide & $4.37 \mathrm{~m} / 14.22 \mathrm{~m} / 17.65 \mathrm{~m}$ \\
\hline Maximum take-off weight & $7,484 \mathrm{~kg}$ \\
\hline Maximum flight distance & $1,550 \mathrm{~km}$ \\
\hline Maximum flight time & $330 \mathrm{~min}$ \\
\hline Maximum operation Altitude & $35,000 \mathrm{ft}$ \\
\hline
\end{tabular}

인공증우(설) 항공실험은 시딩 물질이 반응할 수 있는 대상 지역의 기상 조건(구름, 기온, 기압, 습도, 바람 등)이 일정 시간 유지되는 것이 예측될 때 수행된다. 이를 위해 국립기상과학원에서는 대상 지역에 설치된 지상관측소 자 료와 기상청에서 생산하는 일기도 및 기상 예측모델의 결과 자료를 분석하고, 실험 예정일을 결정한다. 인공증우(설) 항공실험을 결정하는 방법은 NIMS (2019)에 자세하게 기술 되어 있다. 인공증우(설) 항공실험을 결정하기 위한 의사결 정 흐름도는 Fig. 2와 같다.

인공증우(설) 항공실험을 위해 기온이 $0{ }^{\circ} \mathrm{C}$ 이하인 경우 빙정핵 역할을 하는 요오드화은(AgI) 시딩 물질을 이용하고, 기온이 $0{ }^{\circ} \mathrm{C}$ 이상인 경우 응결핵 역할을 하는 흡습성 물질인 염화칼슘 $\left(\mathrm{Cacl}_{2}\right)$ 을 이용하여 실험한다. 요오드화은은 차가 운 구름 속의 과냉각 물 입자를 얼음으로 바꿔 빙정을 생산하 거나 강화해 강수를 유발하고, 염화칼슘은 따뜻한 구름의 응결핵 역할을 한다(NIMS, 2018).

국립기상과학원에서는 연소탄 형태로 제작된 시딩 물질 을 기상 항공기의 양쪽 날개에 장착하고, 실험지역으로 이동 하여 연소시킨다. 이러한 시딩 물질을 뿌리는 것을 시딩 (seeding)이라고 한다. 국립기상과학원의 기상 항공기와 $\mathrm{AgI}$ 연소탄이 장착된 그림은 다음과 같다(Fig. 3).

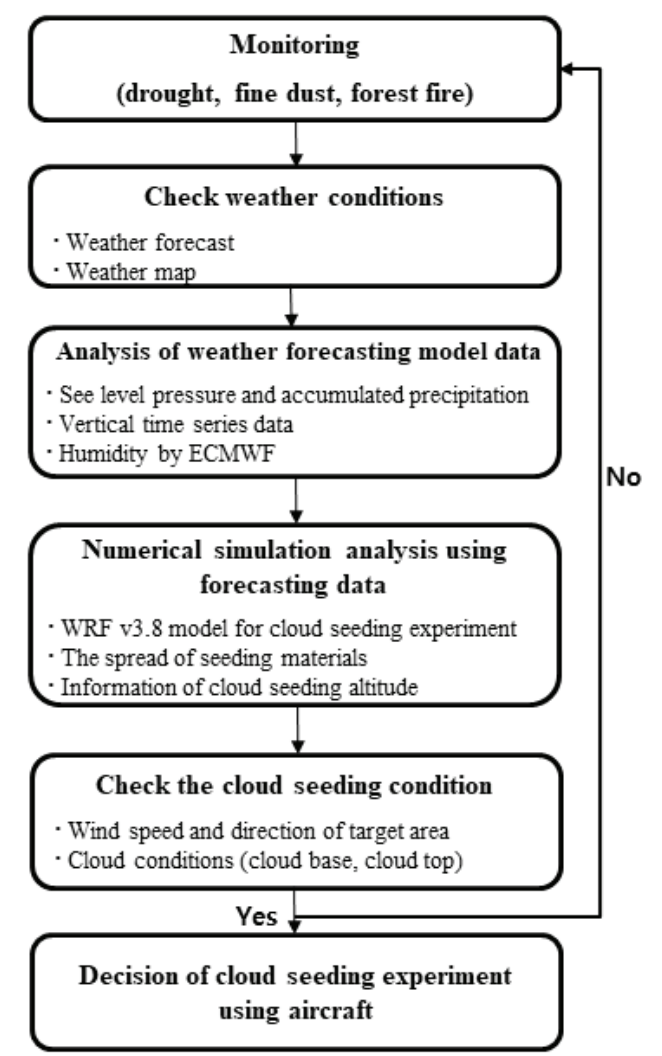

Fig. 2. Flowchart for Cloud Seeding Experiment by Aircraft (NIMS, 2019)

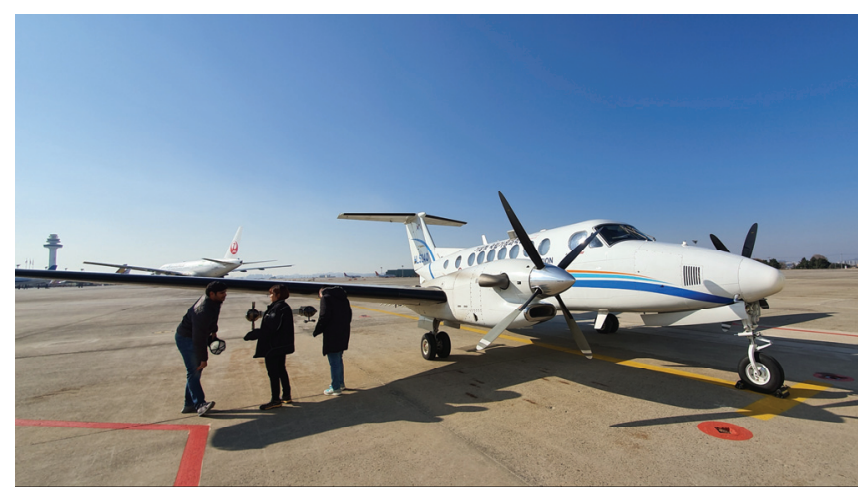

(a)

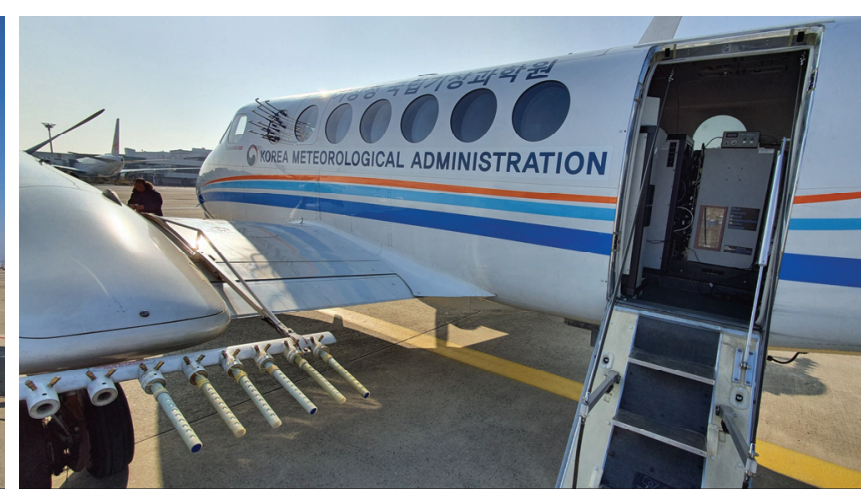

(b)

Fig. 3. NARA (a) and Burn-in-place Cloud Seeding Material (AgI) Flares (b) 
Table 2. International Joint Experiments (IJCO-WCE 2019)

\begin{tabular}{|c|c|c|c|c|}
\hline & Date & Target area & Seeding material & Altitude $(\mathrm{km})$ \\
\hline 1 & 2019. 11. 24. $14: 28 \sim 15: 08$ & The yellow sea & AgI & $3.1,2.5$ \\
\hline 2 & 2019. 11. 25. 11:02 11:37 & \multirow{2}{*}{ Pyeongchang, Gangwon-do } & AgI & 1.9 \\
\hline 3 & 2019. 11. 28. 11:24 11:52 & & AgI & 1.9 \\
\hline 4 & 2019. 12. 01 . $11: 08 \sim 11: 32$ & \multirow{5}{*}{ The yellow sea } & AgI & 1.9 \\
\hline 5 & 2019. 12. 02 . $12: 00 \sim 12: 16$ & & AgI & 1.2 \\
\hline 6 & 2019. 12. $03.12: 14 \sim 12: 31$ & & AgI & 1.6 \\
\hline 7 & 2019. 12. $07.11: 54 \sim 12: 07$ & & AgI & 1.48 \\
\hline 8 & 2019. 12. 17. $11: 52 \sim 12: 25$ & & $\mathrm{Cacl}_{2}$ & 0.9 \\
\hline 9 & 2019. 12. 18. $13: 24 \sim 13: 30$ & The east sea & AgI & 1.2 \\
\hline
\end{tabular}

\section{2 국제공동연구(IJCO-WCE 2019)}

국립기상과학원은 국내 기상조절 실험기술의 실용화를 위한 목적으로 2019년 11월 18일부터 12월 20일까지 미국 Droplet Measurement Technologies (DMT)와 인공증우(설) 국제공동연구 프로젝트(IJCO-WCE 2019)를 수행하였다. 미국 DMT의 기상조절실험 전문가들은 아랍에미리트와 인 도 등 많은 나라와 공동으로 기상조절실험 프로젝트를 진행 하여 기상조절 분야에서 많은 기술을 가지고 있다(Kucera et al., 2010; Tessendorf et al., 2012).

국제공동연구 기간에 총 9 번의 기상 항공기를 이용한 시딩 실험을 수행하였다. 이 기간에 서해안 상공에서 총 6 번, 강원도 평창군 및 강릉시 상공 일대에서 2번, 동해안 상공에서 1 번의 항공실험을 수행하였다. 총 9 번의 항공실험 중 시딩 물질로 요오드화은(AgI)을 8번 사용하였고, 염화칼 슘 $\left(\mathrm{Cacl}_{2}\right)$ 은 1 번만 사용하였다. 국제공동연구 기간에 수행된 항공실험에 대한 요약은 Table 2와 같다.

본 논문에서는 이들 사례 중 강원도 평창군 및 강릉시 상공 일대에서 수행된 11월 25일 사례를 대상으로 DMT에서 설계한 항공실험 방법과 국립기상과학원에서 사용하는 항 공실험 방법을 비교하고, DMT에서 설계한 항공실험 방법으 로 수행된 항공실험의 인공증우(설) 효과를 분석하였다. 서해안과 동해안에서 수행된 실험은 시딩 지역이 내륙에서 $100 \mathrm{~km}$ 이상 떨어진 상공으로 지상 자료(레이더, 지상 관측 소 등)를 활용하는 데 제한이 있어 제외하였고, 11 월 28일 사례는 11 월 25일과 같은 방법으로 실험을 수행하였기에 본 연구에서는 11 월 25 일에 수행된 사례를 대상으로 분석하 였다.

\section{3 대상 지역 및 항공실험 설계 방법}

본 연구의 대상 지역은 강원도 평창군 대관령 부근이다. 국립기상과학원에서는 2006년부터 강원도 평창군 대관령에 구름물리선도센터(Cloud Physics Observation Site, CPOS)를 운영하고 있으며, 겨울철 대관령 지역을 중심으로 인공증우 (설) 실험을 수행하였다(NIMS, 2018). 이곳에는 구름 물리
특성 관측 및 인공증우(설) 지상 - 항공실험의 검증을 위한 지상관측 장비가 구축되어있다. 2015년에는 용평(YPO) 지 점, 2016년에는 오대산 $(\mathrm{ODO})$ 과 진부 $(\mathrm{JBO})$ 지점을 추가하였 으며, 최근에는 대기리(DRO) 지점을 추가하여 관측을 수행 하고 있다. 국립기상과학원에서 운영하는 강원도 평창군 인근의 지상관측소 위치와 관측장비 현황은 Fig. 4 와 같다.

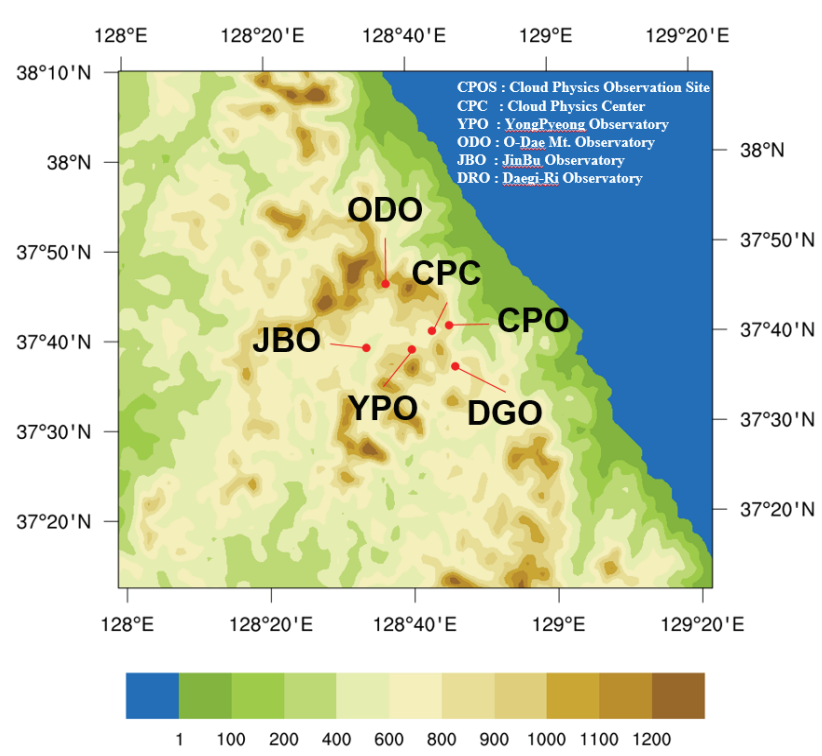

Fig. 4. Location of NIMS Ground Observation Stations (Pyeongchang, Gangwon-do)

국립기상과학원의 항공실험 시딩 방법은 목표지점의 풍 상측에서 유입되는 풍향에 수직으로 왕복하면서 시딩하는 방법을 이용한다(Fig. 5 (a)). 실험이 성공적으로 수행되기 위해서는 시딩 효과가 잘 나타나게 시딩 라인의 설계가 필요하다. 시딩 라인을 설계하는 방법은 다음과 같다. 먼저, 대상 지역에서 시딩 라인까지의 거리는 다음 공식을 이용하 여 결정된다.

$\mathrm{SL}_{\text {distance }}=\mathrm{V}_{\text {ave }} \times \mathrm{T}_{\mathrm{eff}}$ 
여기서, $\mathrm{SL}_{\mathrm{distance}}$ 은 대상 지역에서 시딩 라인까지의 거 리를 의미하며, $\mathrm{V}_{\mathrm{ave}}$ 는 평균 풍향 속도 $(\mathrm{m} / \mathrm{s}), \mathrm{T}_{\mathrm{eff}}$ 는 시딩 효과 시간이며 60 분으로 가정한다. Eq. (1)을 통해 거리가 결정되면 대상 지역의 풍향을 고려하여 시딩 라인의 위치 를 결정하고, 시딩 라인은 Fig. 5(a)와 같이 시딩 라인의 중간지점을 기준으로 좌우 $10 \mathrm{~km}$ 로 설정하여 총 $20 \mathrm{~km}$ 로 설계된다. 이렇게 설계된 시딩 라인에서 항공기로 왕복하 면서 시딩하고, Fig. 5(a)의 관측 라인에서 항공기의 고도를 변경하면서 시딩 전 - 후에 대한 인공증우(설) 효과를 관측 한다.

미국 DMT에서 강원도 평창군 및 강릉시를 대상으로 설계한 항공실험 방법은 Fig. 5(b)와 같다. Fig. 5(b)를 보면 DMT에서는 풍향이 동풍 또는 북동풍일 때, 구름이 산악효과 의 영향을 받는 태백산맥을 기준으로 시딩 라인을 결정하고, $\mathrm{A}$ 와 $\mathrm{B}$ 를 왕복하면서 시딩하고, 시딩 후에는 $\mathrm{B}$ 지점에서 $\mathrm{CPOS}$ 지점으로 이동 후 $\mathrm{C} \rightarrow \mathrm{D} \rightarrow \mathrm{E} \rightarrow \mathrm{CPOS}$ 순으로 관측을 수행하는 것으로 설계하였다.

이 방법은 시딩 후 항공 관측을 지그재그로 설계하여 시딩 물질의 영향을 공간적으로 파악할 수 있게 설계된 것이다. 지금까지 국립기상과학원에서는 Fig. 5(a)와 같이 시딩 후 1 개의 라인을 이용하여 항공 관측을 수행하였다. 그러나 이 방법은 풍속이 강할 때 시딩 라인에서 먼 지역까지 이동하면서 항공 관측을 수행할 수 있지만, 넓은 지역에서 인공증우(설) 효과를 파악하는 데는 한계를 가지고 있다. 이러한 단점을 보완하여 DMT에서는 시딩 물질의 반응시간 을 고려하여 시딩 라인 주변에서 공간적으로 시딩 물질을 관측할 수 있게 설계하였다.

항공실험 후에는 수치 모의, 레이더 자료, 지상관측소 자료, 항공 관측 자료를 이용하여 인공증위(설) 효과를 분석 한다. 먼저, 기상레이더 반사도 자료와 우량계 자료를 이용하 여 대상 지역에 대한 자연 강수의 영향을 분석한다. 다음으로 수치 모의를 통한 시딩 물질 확산장을 이용하여 시딩 물질이 대상 지역에 영향을 미치는지를 확인하고, 시딩 물질이 대상
지역에 영향을 미치는 것이 확인되면 지상관측소에서 강수 량 변화를 확인한다. 마지막으로 기상 항공기에 설치된 기상 관측장비를 이용하여 구름 입자 크기별 수농도, 대기 중 구름 및 강수 입자 변화를 분석한다.

\section{3. 실험 분석 결과}

\section{1 구름 및 기상 현황 분석}

2019년 11월 25일 강원도 평창군 및 강릉시 일대의 기상 상황과 위성영상은 Fig. 6 과 같다. 11 월 25 일은 전국적으로 다층운의 영향을 받았으며, $500 \mathrm{hPa}$ 기압골에 의해 중층운이 점차 동쪽으로 이동하였다. 대관령 지역 인근에는 중상층운 이 존재하였으며, 운정고도는 7 10 km로 나타났다. 대관령 과 북강릉의 연직시계열 자료(Fig. 6(c))를 보면 시딩 시간인 09:00 15:00 (LST)의 풍향은 북동풍, 풍속은 7.5 10.0 m/s, 기온은 약 $-6{ }^{\circ} \mathrm{C}(850 \mathrm{hPa})$ 로 나타났다.

\section{2 시딩 실험 및 비행 경로}

국립기상과학원에서는 2019년 11월 25일 강원도 평창군 및 강릉시 일대에서 기상 항공기를 이용한 인공증우(설) 항공실험을 수행하였다. 이 실험은 북동풍계 구름을 대상으 로 태백산맥을 따라 시딩하고, 시딩 라인 전·후에 대한 인공증우(설) 효과를 관측한 사례이다. 이 실험을 위해 요오 드화은(AgI) 연소탄 24발(양쪽 날개의 각 2발씩)을 사용하였 고, 대상 지역의 상공 $1.9 \mathrm{~km}$ 에서 11 시 02 분부터 37 분까지 총 35 분간 시딩 물질을 살포하였다(Fig. 7).

기상 항공기의 비행경로는 Fig. 8과 같다. 그림에서 분홍색 선은 시딩 경로, 하늘색 선은 시딩 실험 전 구름관측 경로, 파란색 선은 시딩 후 구름관측 경로이다. 먼저, 기상 항공기는 시딩 실험을 위한 고도를 결정하기 위해 대상 지역에 도착하 여 BIKSI->CHERI->A 순으로 시딩 실험 전 구름관측을 수행하였다. 그림에서 확인할 수 있듯이 시딩 실험 전에 구름을 파악하였고, 시딩 고도는 $1.9 \mathrm{~km}$ 로 결정되었다. 다음

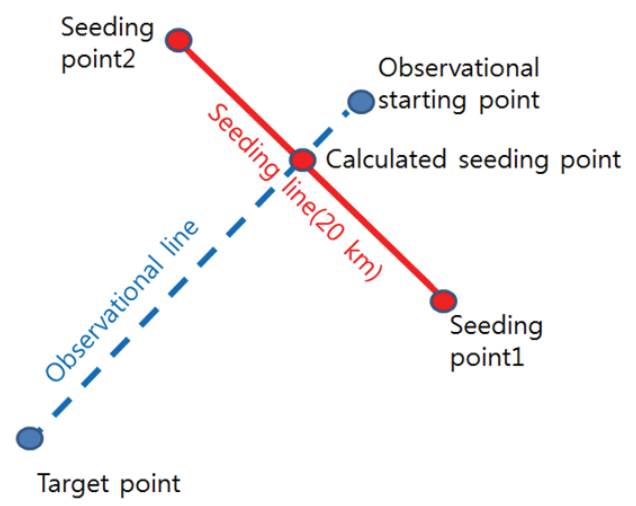

(a) NIMS (Cha et al., 2019)

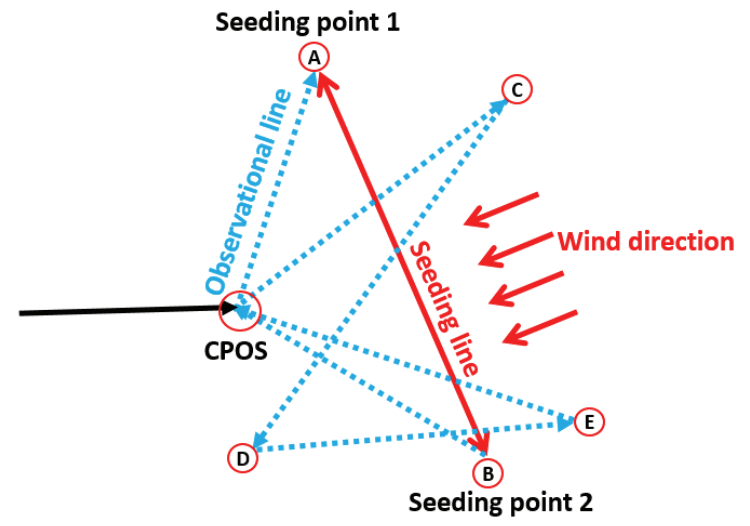

(b) DMT

Fig. 5. Comparison of Cloud Seeding Experiment Aircraft Strategies 


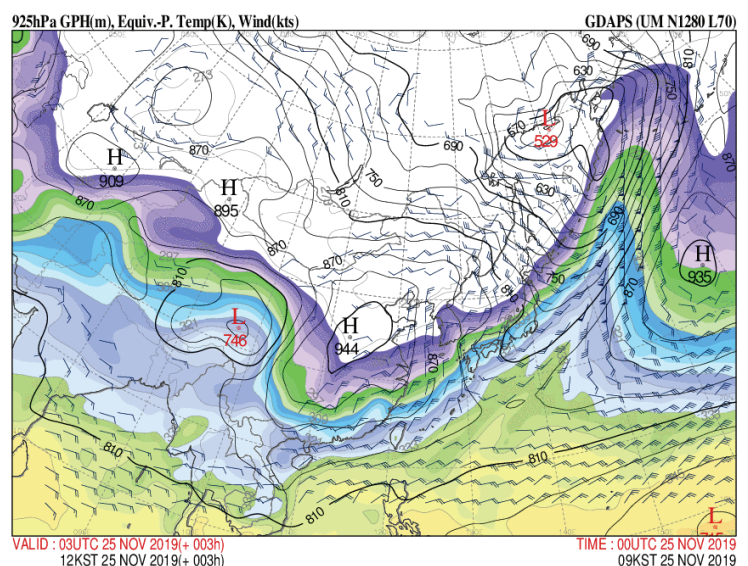

(a) Weather forecast

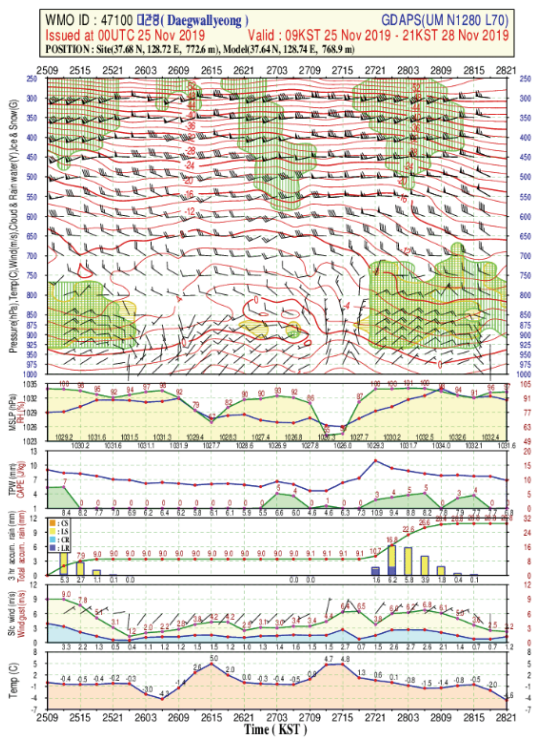

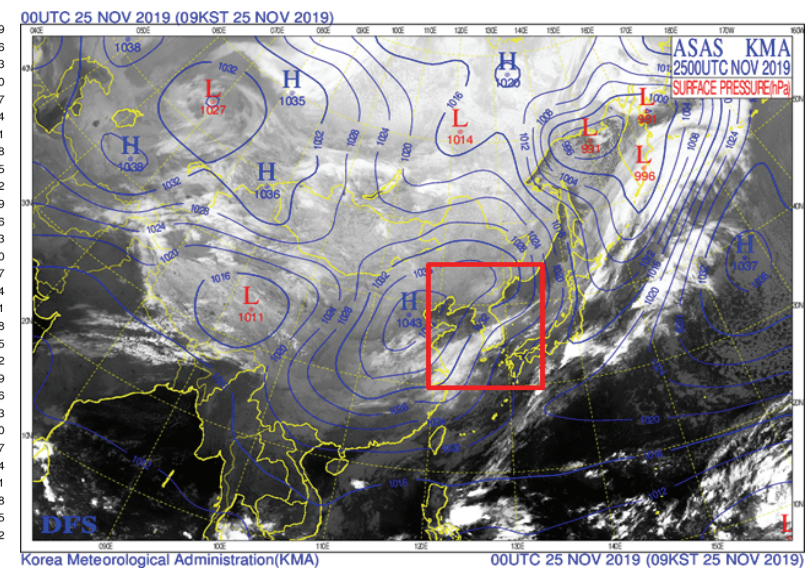

(b) Satellite image

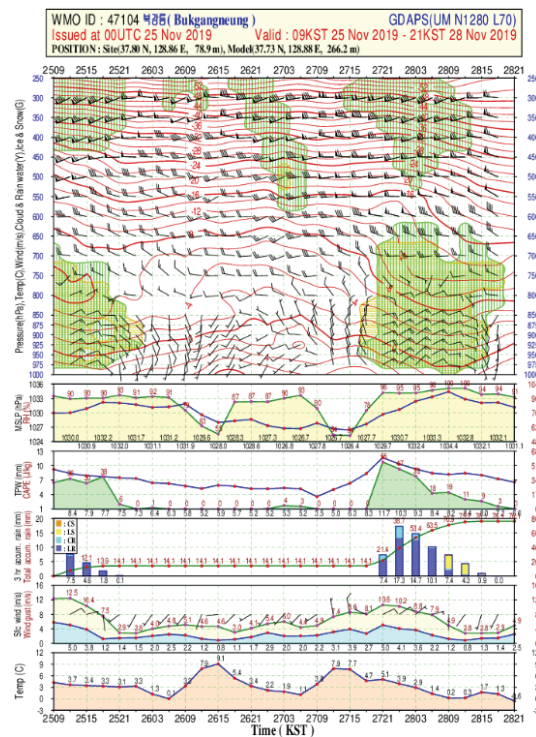

(c) Vertical time series data (left: daegwallyeong, right: bukgangneung)

Fig. 6. Weather Conditions for November 25, 2019
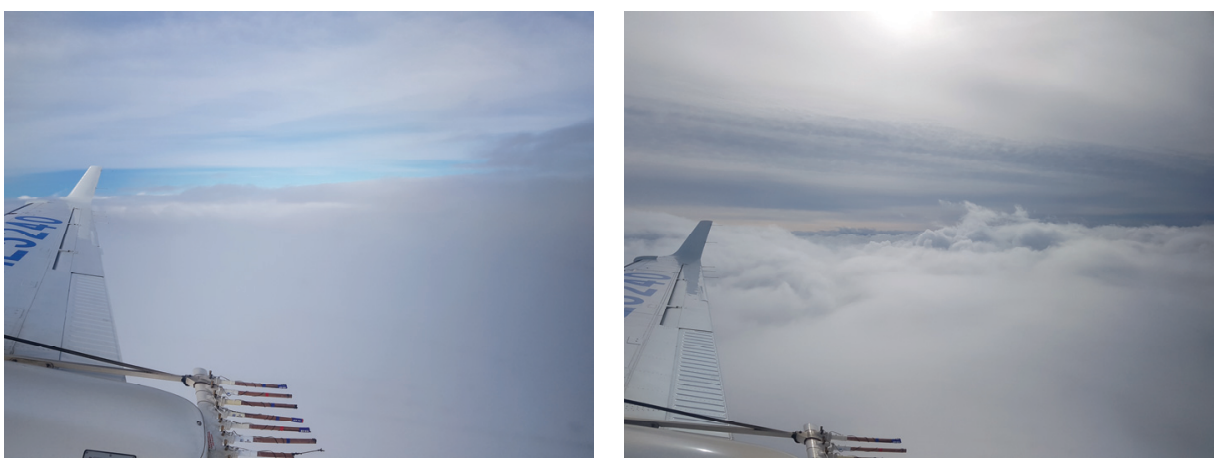

Fig. 7. Cloud Seeding Experiment using the Aircraft

으로 기상 항공기는 고도를 $1.9 \mathrm{~km}$ 로 유지하고 CHERI와 $\mathrm{A}$ 를 왕복 비행하면서 약 35 분간 시딩 물질을 살포하였다. 그리고 시딩 후에는 시딩 실험과 같은 고도를 유지하면서 $\mathrm{BIKSI} \rightarrow \mathrm{B} \rightarrow \mathrm{C} \rightarrow \mathrm{D} \rightarrow \mathrm{BIKSI}$ 순으로 인공증우(설) 실험 효과 를 위한 구름을 관측하였다.
기상 항공기로 관측된 구간별 기상상태 시계열 자료는 Fig. 9와 같고, 이들의 평균값은 Table 3에 나타내었다. 표를 보면 시딩 고도에서의 기온은 약 $-6.5{ }^{\circ} \mathrm{C}$ 이고, 풍속은 7.0 $\mathrm{m} / \mathrm{s}$ 로 나타났다. 풍향은 일부 시간에서 북풍으로 나타났지 만, 대부분은 동풍으로 관측되었다. 

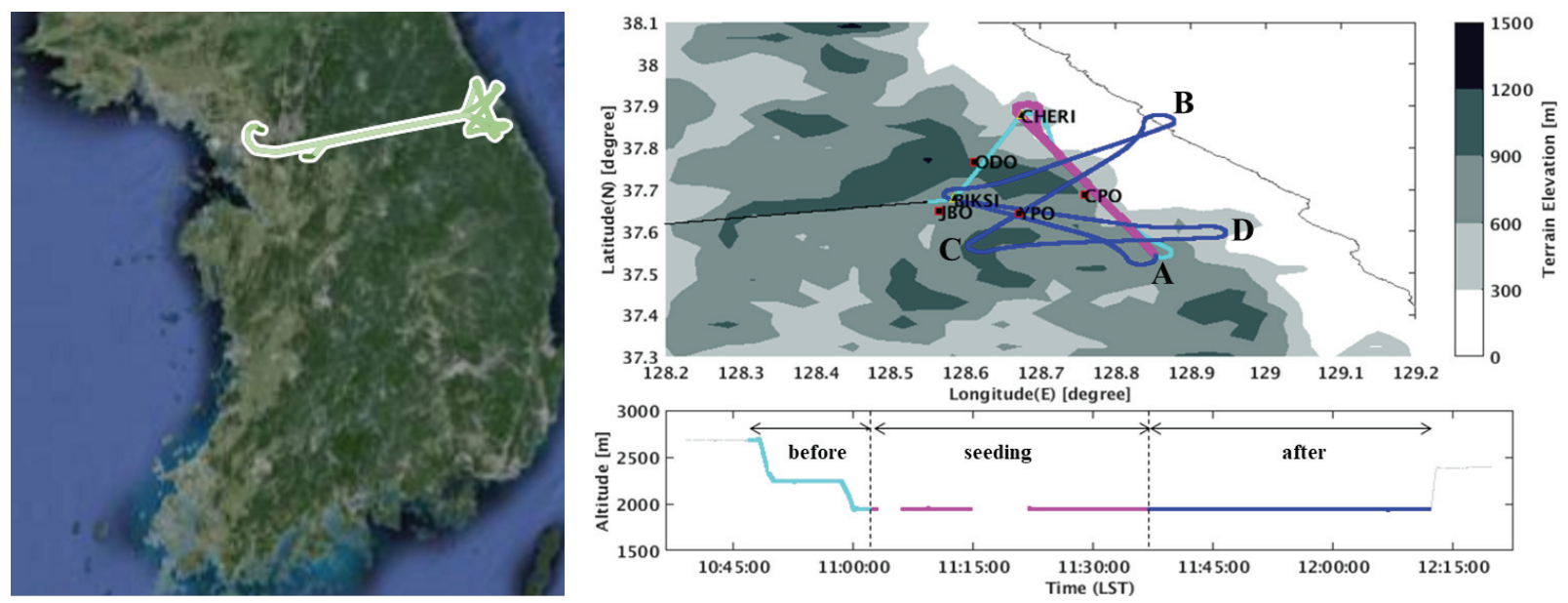

Fig. 8. Aircraft Flight Path and Altitude
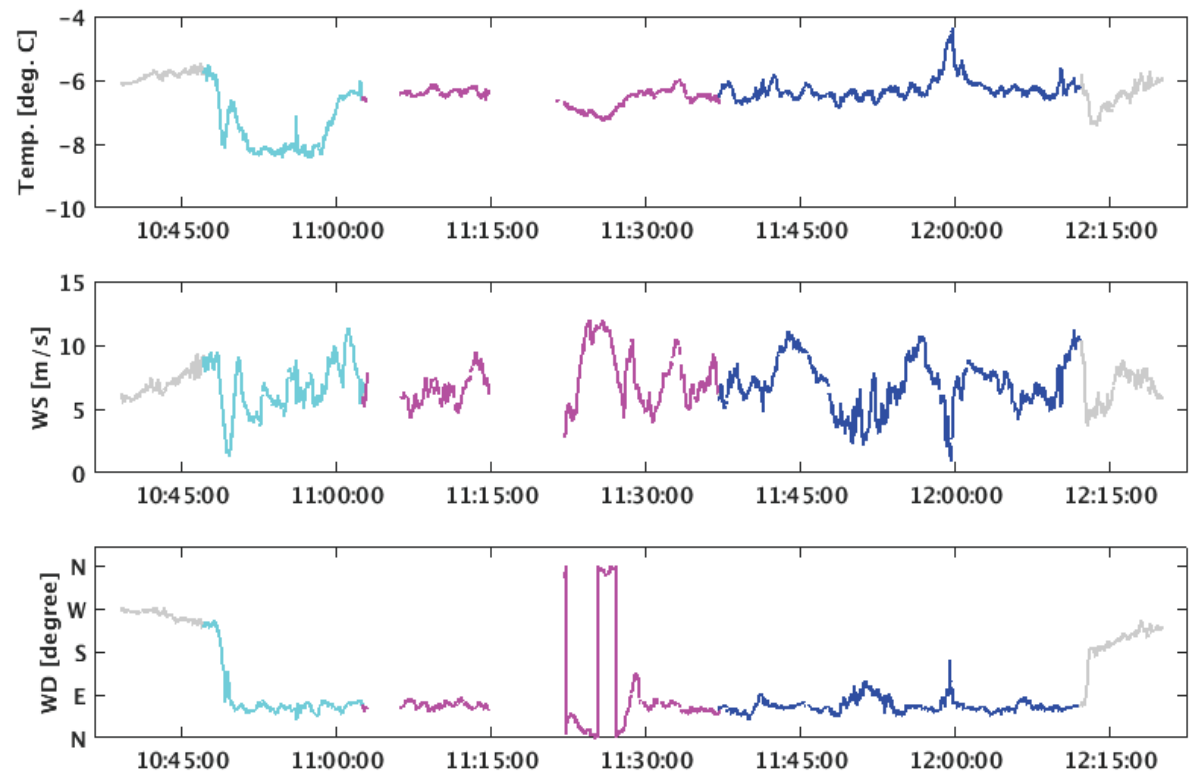

Fig. 9. Time Series Data for Weather Conditions Observed by the Aircraft

Table 3. Weather Conditions Observed by the Aircraft

\begin{tabular}{c|c|c|c}
\hline & Before $(\mathrm{b})$ & Seeding $(\mathrm{S})$ & After (a) \\
\hline Altitude $(\mathrm{km})$ & 2.24 & 1.95 & 1.95 \\
\hline Temperature $\left({ }^{\circ} \mathrm{C}\right)$ & $-7.5( \pm 0.8)$ & $-6.5( \pm 0.3)$ & $-6.3( \pm 0.3)$ \\
\hline Wind speed $(\mathrm{m} / \mathrm{s})$ & $6.7( \pm 2.0)$ & $7.2( \pm 2.0)$ & $7.0( \pm 2.0)$ \\
\hline Wind direction $\left({ }^{\circ}\right)$ & $86( \pm 54)$ & $84( \pm 82)$ & $67( \pm 15)$ \\
\hline
\end{tabular}

\section{3 지상 강수 영향 분석}

실험 전·후에 대한 대상 지역의 자연 강수 영향을 파악하 기 위해 강원도 평창군 및 강릉시 일대에 대한 $1.5 \mathrm{~km} \mathrm{CAPPI}$ 기상레이더 반사도 합성장 자료를 확인하였다(Fig. 10(a)). 그림을 보면 항공 시딩 실험 시간인 11월 25일 11:00 KST에 강원도 평창군 및 강릉시 일대에 자연적인 비(이하 자연
강수)가 존재하는 것으로 나타났다. 시딩 실험 시간인 11시 부터 14 시까지는 태백산맥 동쪽으로 자연 강수가 있는 것으 로 나타났으며, 15 시 이후부터는 강릉 지역에만 자연 강수가 존재한 것으로 나타났다.

추가로 대관령 인근 지역의 자연 강수 영향을 확인하기 위해 국립기상과학원에서 운영하는 6 개 지상관측소 자료를 


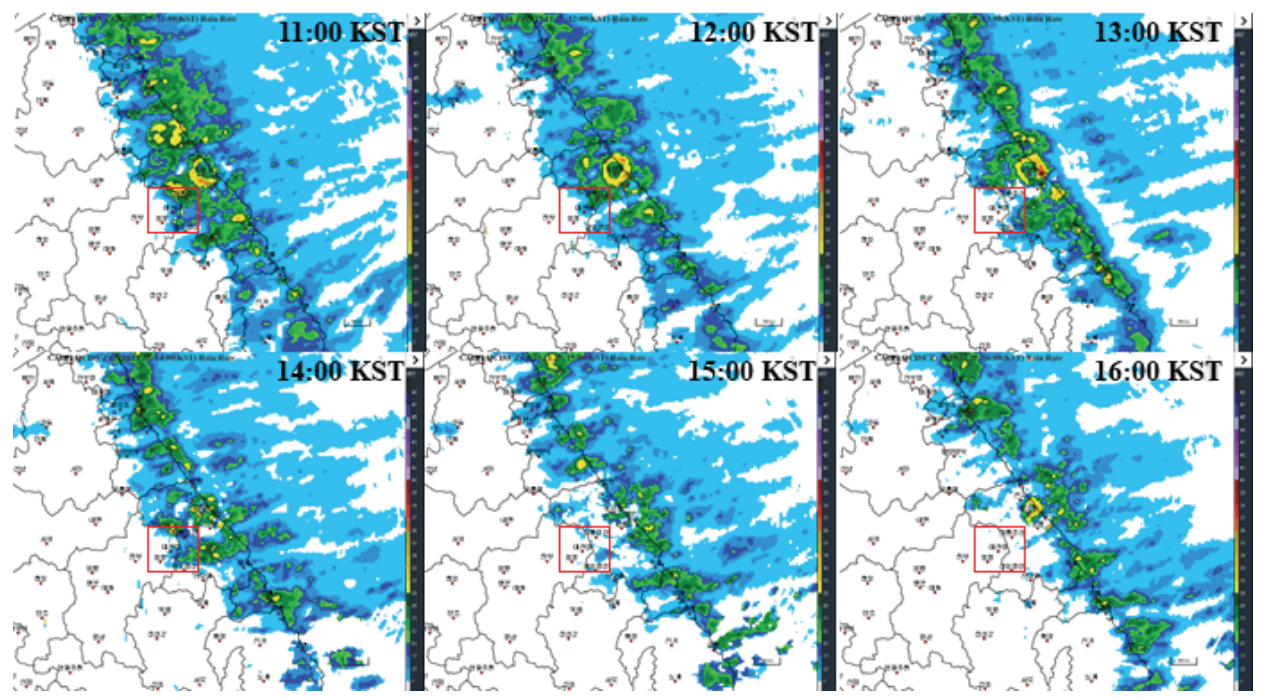

(a) Radar reflectivity (1.5 km CAPPI) measured by $\mathrm{S}$ band radar (box: target area)

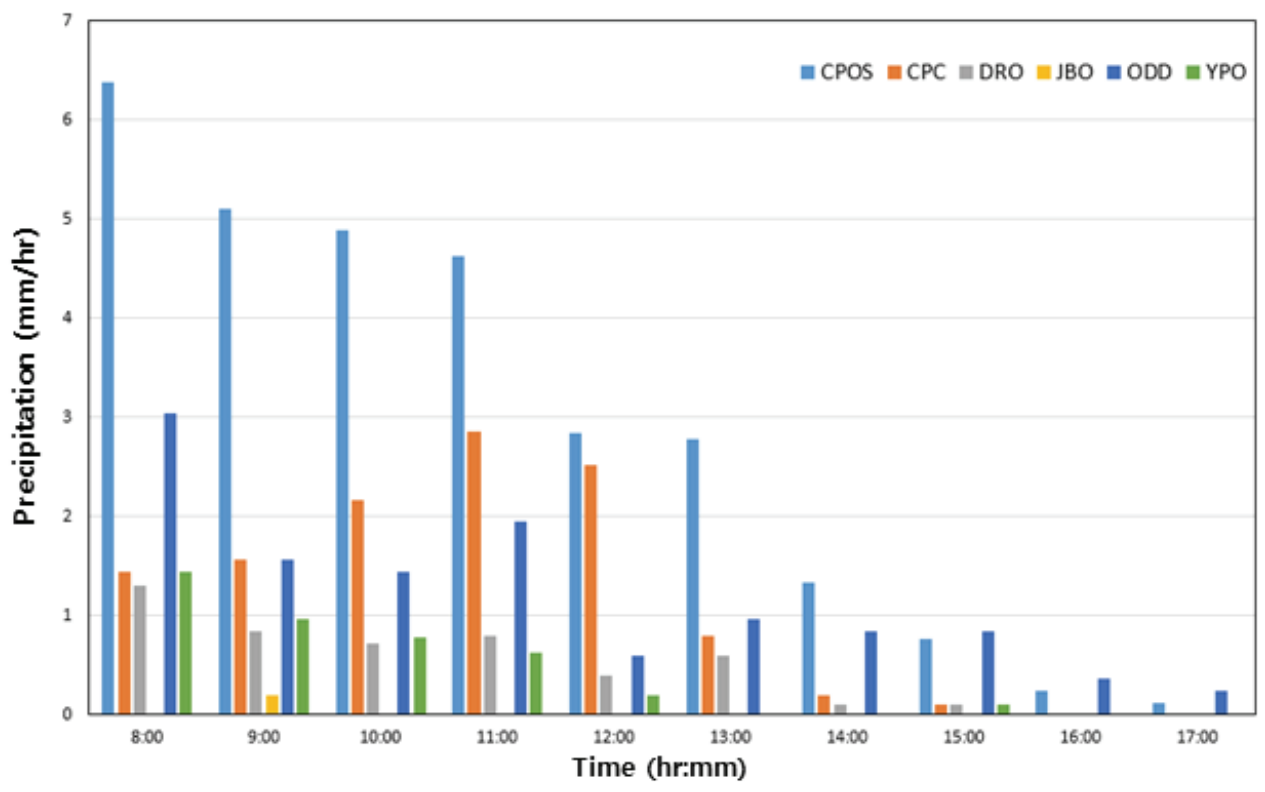

(b) Precipitation data by NIMS ground observation stations

Fig. 10. Check the Target Area Precipitation using Ground Data

확인하였다. Fig. 10(b)를 보면, 강원도 대관령 인근에는 $\mathrm{JBO}$ (진부)를 제외하고 항공 시딩 실험을 수행하기 전부터 자연 강수가 발생하였다. 특히, 각 AWS 관측소에는 14:00까 지 강설이 관측되었다. 레이더 반사도 자료와 지상관측소 강수량 자료를 통해 항공 시딩 실험 전부터 대관령 인근 지역에는 자연 강수가 발생하고 있었으며, 14:00 이후 자연 강수가 점차 줄어들었다.

\section{4 시딩 물질 확산 수치 모의 분석}

본 연구에서는 WRF V3.8 기반의 수정된 모리슨 미세물리 방안을 이용하여 시딩 물질 확산 수치 모델을 통한 인공증우 (설) 효과를 모의하였다. 즉, 기상 항공기에서 연소시킨 시딩 물질이 어떻게 확산하는지를 육안으로 확인할 수 없으므로
수치 모의를 통해 시딩 물질의 분포, 이동 방향, 수농도 등을 확인하는 것이다(Chae et al., 2018). 본 연구에서는 기상청에서 제공하는 UM LDAPS $1.5 \mathrm{~km}$ 의 해상도의 분석 장 자료를 이용하여 $1 \mathrm{~km}$ 격자로 상세 모의하였다.

2019년 11월 25일 11시 02분부터 37분까지의 시딩 라인과 확산장 모의결과는 Fig. 11과 같다. 그림에서 빨간색은 기상 항공기로 시딩 실험을 수행한 비행경로이고, 파란색 음영은 시딩 물질의 수농도를 연직 누적한 분포이다. 그림을 보면, 시딩 라인 왼쪽이 오른쪽보다 시딩 물질의 수농도가 높게 나타났다. 이는 동풍의 영향으로 시딩 물질이 왼쪽으로 확산 한 것으로 보인다. 이는 앞선 Table 3에서 기상 항공기로 관측된 풍향과 일치하는 것으로 나타났다. 또한, 시딩 물질의 수농도는 12 시 30 분까지 높게 나타났으며, 이후 풍속(2.5 


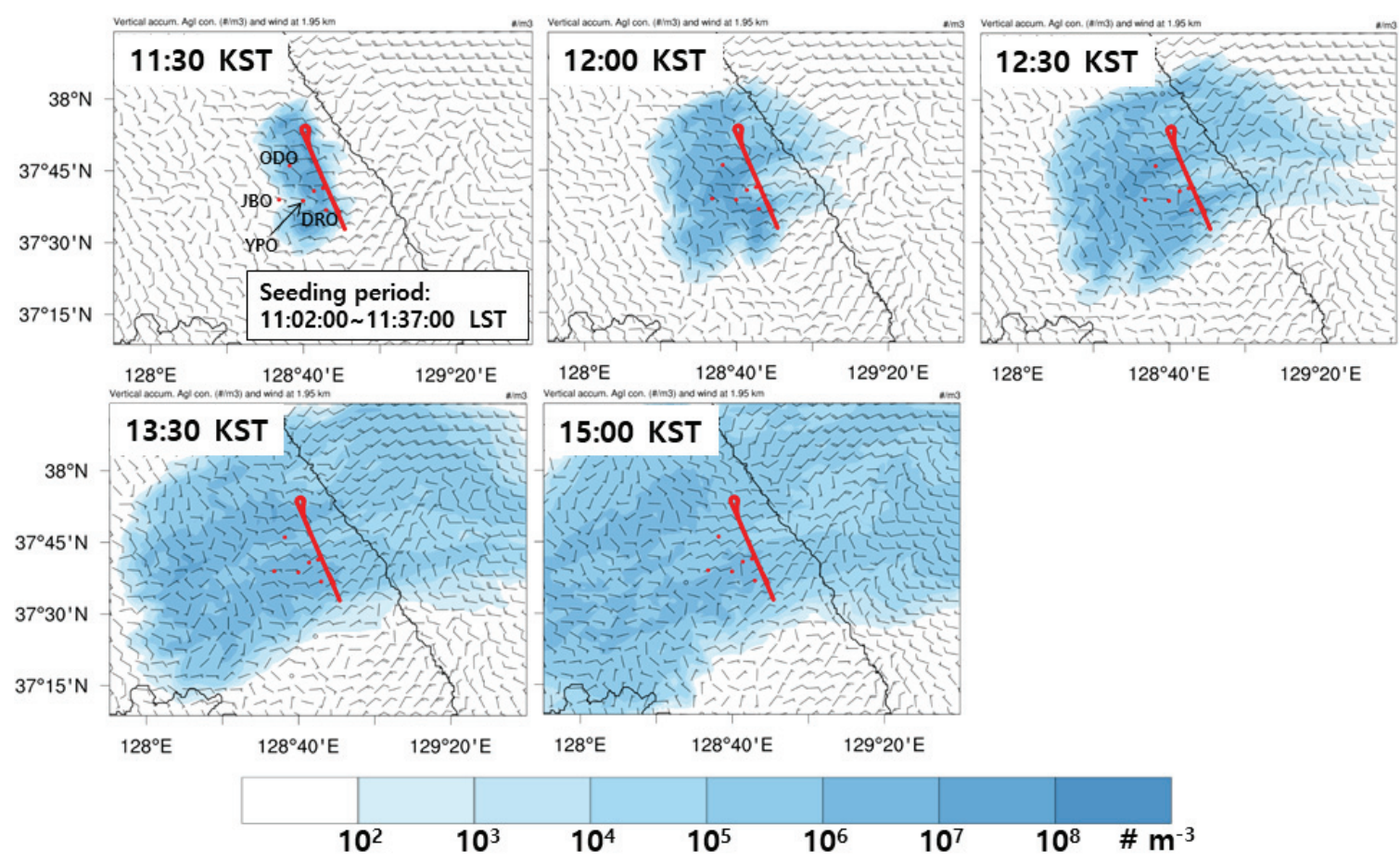

Fig. 11. Vertically Accumulated Seeding Material Concentration Distribution and Wind Field at Cloud Seeding Altitude

$\mathrm{m} / \mathrm{s}$ 이하)이 약한 영향으로 15 시까지 시딩 물질이 대상 지역에 존재하는 것으로 나타났다.

\section{5 기상 항공기 관측자료 분석}

국립기상과학원의 기상 항공기에는 강수 입자 변화를 측정할 수 있는 구름 입자 통합 측정기(Cloud Combination Probe, $\mathrm{CCP}$ )가 설치되어 있다. 이 장비는 구름의 수농도를 측정하는 LWC-100 (Liquid Water Content Sensor), 구름 입자 크기분포를 측정하는 구름 입자 측정기(Cloud Droplet Probe, $\mathrm{CDP})$, 구름 입자 크기분포 및 형태를 측정하는 구름 영상 측정기(Cloud Imaging Probe, CIP)가 통합된 구름 물리 관측장비이다. 또한, 강수 입자를 측정하는 강수 입자 측정기 (Precipitation Imaging Probe, PIP)도 설치되어 있다.

본 연구에서는 앞선 Fig. 8의 비행경로에 대한 $\mathrm{CDP}, \mathrm{CIP}$ 및 PIP로 관측된 구름 및 강수 입자 변화를 분석하였다. 시딩 전·중·후의 $\mathrm{CCP}$ 와 $\mathrm{PIP}$ 로 관측된 구간별 평균수농도 는 Table 4와 같다. 본 연구에서는 시딩 중·후와 관측 고도가 다른 시딩 전은 분석에서 제외하고 시딩 중과 시딩 후에 대한 평균수농도를 비교하였다. Table 4 를 보면 $\mathrm{CDP}$ 로 관측
된 시딩 중과 후의 구름 입자의 평균수농도는 각각 $63 \mathrm{~cm}^{-3}$ 와 $100 \mathrm{~cm}^{-3}$ 로 약 $59 \%$ 증가하였고, $\mathrm{CIP}$ 로 관측된 구름 입자의 평균수농도는 $37.59 \mathrm{~L}^{-1}$ 와 $68.35 \mathrm{~L}^{-1}$ 로 약 $82 \%$ 증가하였다. 또한, PIP로 관측된 강수 입자의 평균수농도는 시딩 중에 $0.01 \mathrm{~L}^{-1}$ 로 거의 관측되지 않았지만 시딩 후에는 $7.52 \mathrm{~L}^{-1}$ 로 증가하였다. 전체적으로 $\mathrm{CCP}$ 와 $\mathrm{PIP}$ 로 관측된 구름 및 강수 입자의 평균수농도는 시딩 중 보다 시딩 후에 증가하는 것으로 나타났다.

본 연구에서는 $\mathrm{CDP}$ 와 $\mathrm{CIP}$ 및 $\mathrm{PIP}$ 로 관측된 강수 입자크 기에 대한 수농도 분포도 확인하였다(Fig. 12). 그림을 보면 작은 강수 입자를 측정하는 $\mathrm{CDP}$ 에서의 강수 입자 크기별 수농도는 전체적으로 시딩 중보다 시딩 후에 증가한 것으 로 나타났다. 이러한 결과는 큰 강수 입자를 측정하는 CIP에 서도 유사하게 나타났다. 이는 시딩 후 시딩 물질이 구름 입자와 반응하여 강수 입자크기가 성장한 것으로 보인다. 또한, PIP는 시딩 중에는 관측되지 않았고, 시딩 후에만 관측되었는데 이는 시딩 전 구름 속에 존재하는 큰 구름 입자가 시딩 물질로 인해 강수 입자로 성장한 것으로 보인다.

Table 4. The Average Water Concentration from CDP, CIP and PIP

\begin{tabular}{c|c|c|c|c}
\hline & Altitude $(\mathrm{km})$ & CDP $\left(\mathrm{cm}^{-3}\right)$ & CIP $\left(\mathrm{L}^{-1}\right)$ & PIP $\left(\mathrm{L}^{-1}\right)$ \\
\hline Before (b) & 2.24 & 92 & 12.98 & - \\
\hline Seeding (S) & 1.95 & 63 & 37.59 & 0.01 \\
\hline After (a) & 1.95 & 100 & 68.35 & 7.52 \\
\hline
\end{tabular}




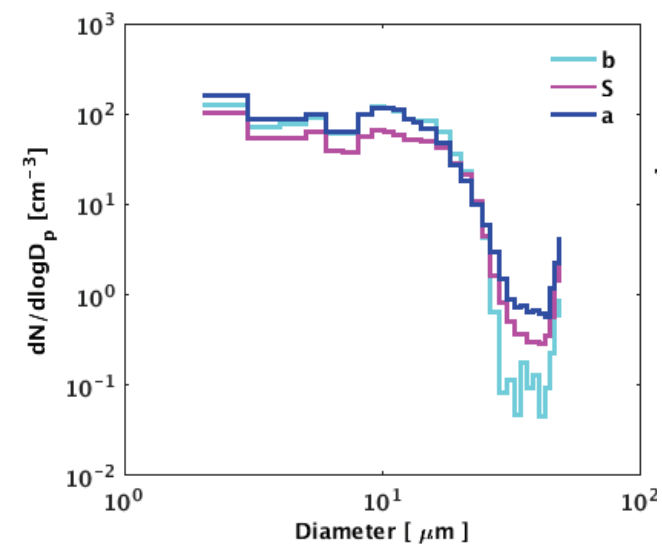

(a)

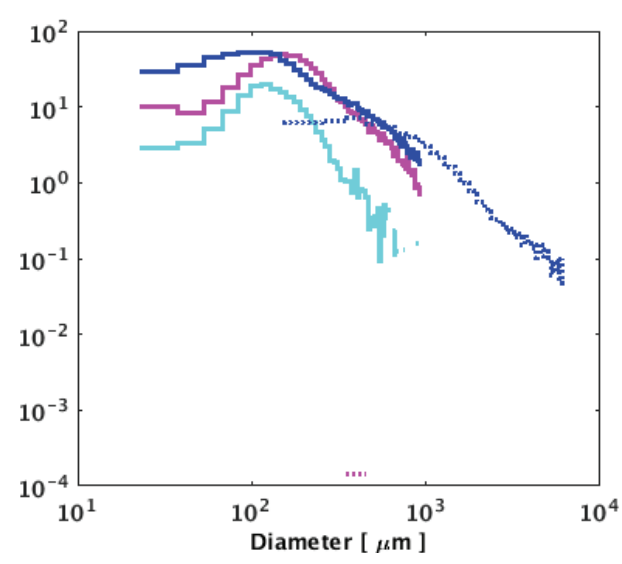

(b)

Fig. 12. DSD of the Aircraft Observed by CDP

(a) and PIP (b)

\section{4. 결 론}

본 연구에서는 대관령을 대상으로 수행된 인공증우(설) 국제공동연구 사례를 레이더 자료, 지상관측소 자료, 수치 모의 자료, 항공 관측 자료를 이용하여 인공증위(설) 효과를 분석하였다. 이번 인공증우(설) 항공실험은 미국 DMT에서 시딩 물질의 반응시간을 고려하여 설계한 항공실험 방법을 이용하여 수행되었다. 결과를 정리하면 다음과 같다.

2019년 11월 25일 사례의 대상 지역에 대한 레이더 자료 와 지상 강우 자료를 분석한 결과, 항공실험을 수행하기 전부터 대상 지역인 강원도 평창군 및 강릉시 일대에 자연 적인 비(자연 강수)가 존재하는 것으로 나타났다. 시딩 실험시간인 11 시부터 14 시까지는 대상지역 및 동해안 일대 에 자연 강수가 있는 것으로 나타났으며, 15 시 이후부터는 강릉시 및 해안가 지역에만 자연 강수가 존재한 것으로 확인되었다.

시딩 물질의 확산을 모의한 수치 모델 분석 결과, 시딩 물질은 시딩 라인의 오른쪽보다 왼쪽에서 수농도가 높게 나타났다. 이는 동풍의 영향으로 시딩 물질이 왼쪽으로 더 확산한 것을 확인되었다. 시딩 물질은 12 시 30 분까지 대상 지역 인근에서 수농도가 높게 나타났으며, 약한 풍속의 영향 으로 15 시까지 대상 지역 인근에 존재하였다.

기상 항공기로 관측된 구름 입자 크기별 평균수농도와 강수 입자는 시딩 중보다 시딩 후에 증가하는 것으로 확인되 었다. $\mathrm{CDP}$ 로 관측된 구름 입자의 평균수농도는 시딩 중보다 시딩 후에 $59 \%$ 증가하였고, $\mathrm{CIP}$ 로 관측된 구름 입자의 평균 수농도는 약 $82 \%$ 증가하였다. 또한, $\mathrm{PIP}$ 로 관측된 강수 입자의 평균수농도는 시딩 중에는 거의 관측되지 않았지만 시딩 후에 관측되었다. 아울러 $\mathrm{CDP}$ 와 $\mathrm{CIP}$ 에서의 강수 입자 크기별 수농도는 전체적으로 시딩 중보다 시딩 후에 증가한 것으로 확인되었다.

상기와 같이 수치 모의 분석 결과와 기상 항공기 관측자료
분석으로 인공증우(설) 효과를 확인하였다. 그러나 이번 사례는 실험 전부터 대상 지역 인근에서 자연 강수가 존재하 였기 때문에 지상 관측 자료를 이용하여 자연 강수와 인공증 우(설)를 구분하는 데 어려움이 있었다. 즉, 실험 전·후에 관측된 지상 자료가 자연 강수에 의한 것인지 인공증우(설) 실험에 의한 것인지를 정확하게 구분할 수 없었다. 자연 강수가 존재하는 기상 상황에서 지상 관측 자료를 이용하여 인공증우(설) 효과를 정확하게 분석하기 위해서는 자연 강수 와 인공증우(설)를 구분하여 분석하는 연구와 기술개발이 필요하다.

\section{감사의 글}

본 연구는 기상청 국립기상과학원「기상항공기 활용기술 개발연구」(KMA2018-00222)의 지원으로 수행되었습니다. 국제공동연구의 총 책임을 맡으신 국립기상과학원 차주완 연구관, 항공실험에 대한 많은 의견을 주신 국립기상과학원 장기호 연구관, 항공실험을 설계한 미국 DMT의 Dr. Duncan Axisa 외 5명(Dr. Darrel gibson Baumgardner, Dr. Gregory lee Kok, Mr. Spencer thomas Faber, Ms. Nicole savage, Mr. Vinayaka mallikarjuna Ruge) 및 기상항공기를 운영한 국립 기상과학원 기상항공기연구팀 및 기상항공기 운영전담팀 (원외) 분들께 깊은 감사를 드립니다.

\section{References}

Baek, S.-G., Jang, H.-W., Kim, J.-S., and Lee, J.-H. (2016). Agricultural drought monitoring using the satellitebased vegetation index. J. Korea Water Resour. Assoc., Vol. 49, No. 4, pp. 305-314.

Cha, J.W., Jung, W., Chae, S., Ko, A.-R., Ro, Y., Chang, K.-H., et al. (2019). Analysis of results and techniques 
about precipitation enhancement by aircraft seeding in Korea. Atmos., Korean Meteorological Society, Vol. 29, No. 4, pp. 481-499.

Chae, S.H., Chang, K.-H., Seo, S., Jeong, J.Y., Kim, B.J., Kim, C.K., et al. (2018). Numerical simulations of airborne glaciogenic cloud seeding using the WRF model with the modified morrison scheme over the Pyeongchang region in the winter of 2016. $A d v$. Meteorol., Vol. 2018, Article ID 8453460. doi:10.1155/2018/8453460

Flossmann, A.I., Manton, M., Abshaev, A., Bruintjes, R., Murakami, M., Prabhakaran, T., et al. (2018). Peer review report on global precipitation enhancement activities. World Weather Research Programme (WWRP) 2018-1, World Meteorological Organization, Geneva, Switzerland.

Geerts, B., Miao, Q., Yang, Y., Rasmussen, R., Breed, D., and Lawrence, B. (2010). The impact of glaciogenic seeding on orographic cloud processes: Preliminary results from the Wyoming weather modification pilot project. Journal of Weather Modification, Vol. 42, No. 1, pp. 105-107.

Geerts, B., Pokharel, B., Friedrich, K., Breed, D., Rasmussen, R., Yang, Y., et al. (2013). The AgI seeding cloud impact investigation (ASCII) campaign 2012: Overview and preliminary results. Journal of Weather Modification, Vol. 45, No. 1, pp. 24-43.

Hashimoto, A., Kato, T., Hayashi, S., and Murakami, M. (2008). Seedability assessment for winter orographic snow clouds over the Echigo Mountains. Scientific Online Letters on the Atmosphere, Vol. 4, pp. 69-72.

Kim, J.E., Park, J.Y., Lee, J.-H., and Kim, T.-W. (2019). Socioeconomic vulnerability assessment of drought using principal component analysis and entropy method. J. Korea Water Resour. Assoc., Vol. 52, No. 6, pp. 441-449.

Kucera, P.A., Axisa, D., Burger, R.P., Collins, D.R., Li, R., Chapman, M., et al. (2010). Feature of the weather modification assessment project in southwest region of Saudi Arabia. Journal of Weather Modification, Vol. 42, No. 1, pp. 78-103.

Kwon, M., Sung, J.H., Kim, T., and Ahn, J. (2018). Drought assessment by bivariate frequency analysis using standardized precipitation index and precipitation deficit: Focused on Han river basin. J. Korea Water Resour. Assoc., Vol. 51, No. 10, pp. 875-886.

Lee, T., and Son, C. (2016). Analyzing the drought event in 2015 through statistical drought frequency analysis. J. Korea Water Resour. Assoc., Vol. 49, No. 3, pp. 177-185.

Li, H., Dai, Y., Wang, H., and Cui, J. (2017). Artificial seeding effects of convective clouds on the opening day of Beijing 2008 summer olympics. J. Geosci. Environ. Protect., Vol. 5, No. 4, pp. 118-138.

National Institute of Meteorological Research (NIMR). (2009). Weather modification. Paju: Gimmyoungsa.

National Institute of Meteorological Sciences (NIMS). (2016). Research on precipitation enhancement in Japan.

National Institute of Meteorological Sciences (NIMS). (2018). Precipitation enhancement principle and application technology.

National Institute of Meteorological Sciences (NIMS). (2019). Precipitation enhancement manual using aircraft.

Ohtake, H., Murakami, M., Orikasa,, N., Hashimoto, A., Saito, A., and Kato, T. (2014). Statistical validation of a cloud resolving model using aircraft observations of orographic snow clouds. J. Meteor. Soc. Japan, Vol. 92, No. 4, pp. 287-304.

Pokharel, B., and Geerts, B. (2014). The impact of glaciogenic seeding on snowfall from shallow orographic clouds over the Medicine Bow mountains in Wyoming. Journal of Weather Modification, Vol. 46, No. 1, pp. 8-28.

Schaefer, V.J. (1946). The production of ice crystals in a cloud of supercooled water droplets. Science, Vol. 104, No. 2707, pp. 457-459.

Silverman, B.A., and Sukarnjanaset, W. (2000). Results of the Thailand warm-cloud hygroscopic particle seeding experiment. J. Appl. Meteor., Vol. 39, No. 7, pp. 1160-1175.

Sohn, K.H., Bae, D.H., and Ahn, J.H. (2015). Projection and analysis of drought according to future climate and hydrological information in Korea. J. Korea Water Resour. Assoc., Vol. 47, No. 1, pp. 71-82.

Tessendorf, S.A., Bruintjes, R.T., Weeks, C., Wilson, J.W., Knight, C.A., Roberts, R.D., et al. (2012). The Queensland cloud seeding research program. Bulletin of American Meteorological Society, Vol. 93, No. 1, pp. 75-90.

Vonnegut, B. (1947). The nucleation of ice formation by silver-iodide. J. Appl. Phys., Vol. 18, No. 7, pp. 593-595.

World Meteorological Organization (WMO). (2009). Experts agree on a universal drought index to cope with 
climate risks. WMO Press Release No. 872.

Yoo, J.Y., Yu, J.S., Kwon, H.-H., and Kim, T.-W. (2016).

Determination of drought events considering the possibility of relieving drought and estimation of design drought severity. J. Korea Water Resour. Assoc., Vol. 49, No. 4, pp. 275-282.

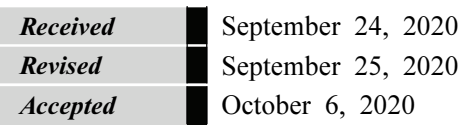

Received September 24, 2020

September 25,2020

October 6, 2020 